\title{
Ascorbic Acid (Antioxidant) in Aegle Marmelos and Moringa Oleifera and Effect of Growth Regulators and Salts on it in Vitro
}

\author{
Kavita Soni ${ }^{1}$, Asha Goswami ${ }^{2}$ \\ Plant Tissue Culture and Biotech. Lab, Department of Botany, Govt. Dungar College, Bikaner (Raj.), India
}

\begin{abstract}
Aegle marmelos and Moringa oleifera are two medicinally important plant species. Unorganized tissues of these plants were established on MS medium supplemented with $1.0 \mathrm{mg} / \mathrm{L} B A P+2.0 m g / L$ 2,4-D and $1.5 m g / L$ BAP $+1.5 m g / L$ 2,4-D respectively (standardized MS medium). Parts of established tissues were transferred to standardized (Sd) MS medium fed with various concentrations $(1,2,3 \mathrm{mg} / \mathrm{L})$ of growth regulators ( IAA, NAA ) and (10,20,30mg/L ) salts ( $\mathrm{NaCl}, \mathrm{KCl}$ ) separately. Tissues at the maximum GI (in all samples) were harvested, dried, powdered and analyzed for estimation of ascorbic acid. Maximum amount of ascorbic acid was calculated in callus fed with $2 \mathrm{mg} / \mathrm{L} \mathrm{IAA,} \mathrm{NAA}$ and $10 \mathrm{mg} / \mathrm{L} \mathrm{NaCl}$ and $\mathrm{KCl}$ in Aegle marmelos as well as Moringa oleifera.
\end{abstract}

Keywords: Aegle marmelos, Moringa oleifera, antioxidant, growth regulators, salts

\section{Introduction}

Aegle marmelos Corr. commonly known as "Bael" is a medium sized slow growing deciduous, spiny, woody fruit tree of tropics. It belongs to family Rutaceae. Bael is a sacred tree, dedicated to Lord Shiva. It is extensively planted near Hindu temples for its leaves and wood used in worship and edible fruits in indigenous medicines. Pharmaceutically A. marmelos is having antibacterial, antihistaminic, anti inflammatory, anticonvulsant, anti stress, adaptogenic, antipyretic, antifertility, analgesic, hepato protective, insecticidal, hypoglycemic, cardiotonic, immune modulatory and wound healing activities.

M. oleifera commonly called "Sigru" belongs to family Moringaceae. All parts of M. oleifera tree such as root, root bark, leaves, flowers, unripe pods, seeds, seed oil are used in Ayurvedic system of medicine. Sigru is used externally as well as internally. Externally, the paste of its leaves and bark skin is applied in boils to subside the swelling and inflammation. Internally Sigru is used in vast range of diseases. Pods are recommended in loss of appetite. It is also beneficial in treatment of worms anorxia, ascites, tumors, abdominal pain, paralysis, joint pain and gout.

Antioxidant is simply a molecule that prevents another molecule from oxidizing. Since there are many processes in the body which result in oxidation. The intake of antioxidant is essential to counteract some of the negative results of the buildup of too many oxidized molecules in the body.

Primary metabolites are produced as a result of photosynthesis by which green plants utilize solar energy to yield the photosynthetic product-Carbohydrate. Besides this process some other primary synthetic processes also occur in plants which yield certain vital products such as proteins, amino acids, minerals and other nutritive contents, ascorbic acid, lipids, vitamins, nucleotide and energy compounds like alcohols, organic acids etc.
Ascorbic Acid or Vitamin ' $\mathbf{C}$ ' is claimed as a „Cure alle for many human diseases and problems from cancer to common cold. Ascorbic acid is required in synthesis of collagen, neurotransmitters, steroid hormones etc. Vitamin $\mathrm{C}$ promotes the healing of wounds, bone fractures, bruises, hemorrhages, bleeding gums and forms the protective barrier between infections or disease and the surrounding healthy tissue. As an antioxidant it has many beneficial functions in combating many diseases and infections and also promotes proper calcium absorption. In plants, ascorbic acid is essential for photosynthetic activity via the detoxification of super oxide and hydrogen peroxide $\left(\mathrm{H}_{2} \mathrm{O}_{2}\right)$ in chloroplasts in the absence of catalyses. Thus, it acts as a reducing agent in biological systems. It also assists in healthy cell development as well as normal tissue growth and repair. Vitamin $\mathrm{C}$ is a water soluble vitamin.

Free endogenous ascorbic acid production has been reported in tissue culture of Momordica charantia and Emblica officinalis (Mohan et al.,1974), Datura metel and Datura tatula ( Nag et al., 1974 ), Trigonella foenum-graceum ( Jain et al., 1975 ), Ephedra foliata, Helianthus annus, Agave wightii and Tephrosia purpurea (Khanna et al., 1977) ; Solanum xanthocarpum (Manot, 1977), Atropa belladona (Sharma, 1977), Papaver somniferum (Gaur, 1978, Khanna et al., 1977 ), Daucus carota (Sogani, 1978), Solanum nigrum (Rathore et al., 1979), Tribulus alatus and Zygophyllum simplex (Jit et al., 1986), Lycium bararum (Nag and Grover, 1987),Eclipta alba (Mathur,1988) Seetzenta orientatis (Sethia,1988), Calligonum polygonoides and Lasiurus sindicus (Bhojak,1991), Tinospora cordifolia (Goswami and Yadav,1994),Lycium barbarum (Mukhi, 1995), Peganum harmala (Badia, 1999), Arabidopsis cell suspension cultures (Davery et al., 1999), Ribes nigrum (Viola et al., 2000),Vigna aconitifolia (Tyagi, 2002),Capparis decidua and Ziziphus sp. (Chauhan, 2003),Cassia angustifolia (Reddy, 2005), Balanitis aegyptiaca (Bedawat, 2006), Ailanthus excelsa (Rao, 2007), Adhatoda vasica and Barleria prionitis (Deepa, 2009), Cocculus pendulus and Tinospora cordifolia (Yadav, 2010), Moringa oleifera(Talreja, 2010), Terminalia arjuna 


\section{International Journal of Science and Research (IJSR) ISSN (Online): 2319-7064 \\ Index Copernicus Value (2013): 6.14 | Impact Factor (2014): 5.611}

(Sharma,2012)., three medicinal plants (Khandelwal et al., 2014).

\section{Materials and Methods}

Unorganized tissue of Aegle marmelos and Moringa oleifera were established on MS medium supplemented with $1 \mathrm{mg} / \mathrm{L}$ BAP+2.0mg/L 2,4-D and $1.5 \mathrm{mg} / \mathrm{L} \mathrm{BAP}+1.5 \mathrm{mg} / \mathrm{L}$ 2,4-D respectively ( standardized MS media for both species). Parts of established tissues were transferred to standardized (Sd) MS medium fed with various concentrations $(1,2,3 \mathrm{mg} / \mathrm{L})$ of growth hormones ((IAA, NAA) and $(10,20,30 \mathrm{mg} / \mathrm{L})$ salts $(\mathrm{NaCl}, \mathrm{KCl})$ separately. GI was calculated in all samples. Tissues at the maximum GI (grown on Sd MS medium, Sd MS medium with all variations of growth regulators and salts in both plant species ) were harvested, dried, powdered and analyzed for estimation of ascorbic acid.

\section{Extraction Procedure}

Ascorbic acid was estimated by Chinoy (1962) method. Dried plant parts as well as cultured tissue at the age of maximum GI, were weighed separately, crushed in a mortar in $2 \%$ Meta Phosphoric Acid (MPA) (100 mg cultured tissue in $1 \mathrm{ml}$ of MPA) and allowed to macerate for one hour. These were then centrifuged separately at low speed (2500 $\mathrm{rpm}$ ) for fifteen minutes, the residues were discarded and the supernatants were used for the estimation of ascorbic acid following the procedure of Jensen (1962).

Each of the $1 \mathrm{ml}$ test solutions were mixed with $2 \mathrm{ml}$ of $5 \%$ MPA and kept for 30 minutes without stirring at room temperature. $5 \mathrm{ml}$ of n-amyl alcohol and $3.2 \mathrm{ml}$ of dye (5 $\mathrm{mg} / 100 \mathrm{ml}, 2$, 4-dichlorophenol indophenol) were added and air bubbled through the lower layer. Each of the test tubes was stoppered tightly, the mixture was shaken vigorously and the upper layer was used for the estimation of ascorbic acid.

The Spectronic-20 colorimeter (Bausch and Lomb) was adjusted at wavelength of $546 \mathrm{~nm}$ and set at $100 \%$ transmittance using a mixture of $1 \mathrm{ml}$ of the extract, $2 \mathrm{ml}$ of 5\% MPA, $5 \mathrm{ml} \mathrm{n}$-amyl alcohol and $3.2 \mathrm{ml}$ distilled water (blank solution) before taking test samples.

Ascorbic acid content present in $1 \mathrm{ml}$ of extract was measured by using the regression formula:

$\mathrm{Y}=\mathbf{0 . 1 1 0 3}-(\mathbf{0 . 1 4} \mathrm{X}$ O.D.)

Where, $\mathrm{Y}=$ Concentration of ascorbic acid in $\mathrm{mg}$,

O.D. $=$ Optical Density

Ascorbic acid content per 100 gm dry weight was calculated as follows:

Free ascorbic acid $=\frac{A \times V}{W} \times 1000 \times 100$

Where, $\mathrm{A}=\mathrm{Y}=\mathrm{mg}$ ascorbic acid / $\mathrm{ml}$ of original extract

$\mathrm{V}=$ total volume of the original extract (in $\mathrm{ml}$ )

$\mathrm{W}=$ weight of the plant tissue sample (in $\mathrm{mg}$ ) used for analysis

\section{Results and Discussion}

Maximum GI was observed at the age of eight weeks in standardized (Sd) MS medium and standaized MS media supplemented with various concentrations $(1,2,3 \mathrm{mg} / \mathrm{L})$ of growth hormones ( IAA and NAA ) and salts ( $\mathrm{NaCl}$ and $\mathrm{KCl}$ at $10,20,30 \mathrm{mg} / \mathrm{L}$ ) in A. marmelos and M. oleifera . Calli were harvested at maximum GI from all the samples separately in both plants and analysed for ascorbic acid content.

It was observed that amount of ascorbic acid was increased in callus fed with growth regulators IAA and NAA. Increase was continuous from Sd MS medium to Sd MS medium fed with $1 \mathrm{mg} / \mathrm{L}$ to $\mathrm{Sd}$ MS medium fed with $2 \mathrm{mg} / \mathrm{L}$ IAA and NAA but after that amount decreased in Sd MS medium fed with $3 \mathrm{mg} / \mathrm{L}$ IAA and NAA separately in both plant species. The amount calculated in calli fed with $3 \mathrm{mg} / \mathrm{L}$ IAA and NAA was even lower than amount of ascorbic acid present in callus grown on Sd MS medium. Maximum amount of ascorbic acid was calculated in callus fed with $2 \mathrm{mg} / \mathrm{L}$ IAA and NAA in A. marmelos as wll as M. oleifera .

In calli fed with salts $\mathrm{KCl}$ and $\mathrm{NaCl}$, the amount of ascorbic acid was increased from Sd MS medium to calli fed with 10 $\mathrm{mg} / \mathrm{L}$ and then decreased from $10 \mathrm{mg} / \mathrm{L}$ to $20 \mathrm{mg} / \mathrm{L}$ upto 30 $\mathrm{mg} / \mathrm{L}$ in both plant species. Maximum amount was calculated in calli fed with $10 \mathrm{mg} / \mathrm{L} \mathrm{NaCl}$ and $\mathrm{KCl}$ in $\boldsymbol{A}$. marmelos as wll as M. oleifera.

Grotwh hormones showed positive response than salts as amount was comparatively higher in calli fed with growth hormones than salts in both plant species. M. oleifera has higher amount of ascorbic acid than A. marmelos in all samples.

\section{References}

[1] Aberg, B. (1958). Ascorbic acid (Formation, storage, mobilization and transformation of carbohydrates). In: Encyclopedia of Plant Physiology. Ruhland, W. (Ed.) Springer Verlag, Berlin. 6:479-499.

[2] Badia, N. (1999). Influence of plant growth regulators and precursors on the production of primary and secondary metabolites in tissue culture of Peganum harmala Ph. D. Thesis, M. D. S. Univ., Ajmer, Rajasthan.

[3] Bedawat, S. (2006). Evaluation of Balanites aegyptiaca - an arid zone medicinal plant for its phytochemically important metabolites. Ph.D. Thesis, M.D.S. Univ. Ajmer, Rajasthan.

[4] Bhojak, S. (1991). Phytochemical investigation of some fodder plants of arid zone of Rajasthan in vivo and in vitro. Ph. D. Thesis, M. D. S. Univ., Ajmer, Rajasthan.

[5] Chauhan, N. (2003). Pharmaceutically important compounds from in vivo and tissue cultures of Capparis and Ziziphus growing in arid zone of Rajasthan. Ph.D. Thesis. M.D.S. University, Ajmer.

[6] Deepa (2009). In vivo and in vitro comparative studies of primary and secondary metabolites of two medicinally important plants belonging to family Acanthaceae.Ph. D. Thesis, M. G. S. Univ., Bikaner, Rajasthan.

[7] Davery, M. W.; Gilot, C.; Persiau, G.; Ostergaard, J.; Han, Y.; Bauw, G. C. and Van, Montagu, M. C. 


\section{International Journal of Science and Research (IJSR) \\ ISSN (Online): 2319-7064 \\ Index Copernicus Value (2013): 6.14 | Impact Factor (2014): 5.611}

(1999). Ascorbate biosynthesis in Arabidopsis cell suspension culture. Plant Physiol. 121:535-543.

[8] Gaur, M. (1978). Production of primary and secondary products from in vitro plant tissue cultures. Ph. D. Thesis, Univ. of Rajasthan, Jaipur.

[9] Goswami, A. and Yadav, L. (1994). Seasonal evaluation of ascorbic acid contents of two plant species. Physiol. Res. 7 (1) 87-88.

[10] Goswami, A. and Solanki, S. (2005). Endogenous Ascorbic acid provided to the animals by Thar desert plants. Oikoassay 17 (1 \& 2) 17-19.

[11] Goswami, A.; Deepa and Reddy, A. (2008).Endogenous ascorbic acid from some medicinal plants in vivo and in vitro Ind. J. Phyto. Res. 21 (2) 293-231.

[12] Jain, S. C.; Nag, T. N.; Mohan, S and Khanna, P. (1975). Ascorbic acid metabolism and growth in plant tissue cultures. Science and Culture 41: 292- 293.

[13] Jit, S.; Shekhawat, S. S. and Nag, T. N. (1986). Free ascorbic acid and growth of tissues from in vitro tissue cultures. Comp. Physiol. Ecol. 11(3)103-107.

[14] Khandelwal, S.; Rishi, A. and Khurana, S.M.P (2014). Estimation of primary and secondary metabolites from leaves of three medicinal plants. International Res. J. of Pharmacy. 5(10)783-785.

[15] Khanna, P.; Kamal, R. ; Taparia, R. and Jain, S.C. (1977). A quantitative estimation of free ascorbic acid and growth of tissue from in vitro tissue cultures. Vidya. B. Sciences. Vol. XX (1)1-6.

[16] Mathur, K. (1988). Primary and scondary metabolites from some arid zone plants of Rajasthan growing in vivo and in vitro. Ph. D. Thesis, Univ. of Rajasthan, Jaipur.

[17] Mohan, S.; Nag, T. N.; Jain, S. C. and Khanna, P. (1974). Free ascorbic acid from plant tissue cultures. Vidya B. Science 17: 8-13.
[18] Mukhi, B. (1995). Influence of plant growth regulators on product biosynthesis in tissue culture of Lycium barbarum Ph. D. Thesis, M.D.S. Univ., Ajmer, Rajasthan.

[19] Nag, T. N.; Jain, S. C.; Mohan, S. and Khanna, P. (1974). Ascorbic acid metabolism and growth in Datura tissue culture. Ind. J. Pharm. 36:49-50.

[20] Nag, T. N. and Grover, S. (1987). Free ascorbic acid from Lycium barbarum tissue culture. Ind. J. Bot. 10(1)14-16.

[21] Rathore, A. K.; Sharma, G. L. and Khanna, P. (1979). Free ascorbic acid from Solanum nigrum tissue cultures. Ind. J. Bot. 2:42-44.

[22] Reddy, A. (2005). Biochemical investigation of economically important plant of arid zone of Rajasthan-Cassia angustifolia - in vivo and in vitro. Ph. D. Thesis, M. D. S. Univ., Ajmer, Rajasthan.

[23] Sethia, M. (1988). Phytochemical analysis of some arid zone plants of Rajasthan growing in vivo and in vitro. Ph.D. Thesis. University of Rajasthan. Jaipur. India.

[24] Sharma,P.( 2012). In vivo and in vitro phytochemacal studies of medicinally useful tree Terminalia arjuna. Ph.D. Thesis, M.G.S. Univ. Bikaner, Rajasthan .

[25] Sogani, M. (1978). Production of primary and secondary products from in vivo and in vitro tissue cultures. Ph. D. Thesis, Univ. of Rajasthan, Jaipur.

[26] Tyagi, S. (2002). Comparative analysis of phytochemical in Moth bean cultivars growing in field

[27] and in tissue culture. Ph. D. Thesis, M. D. S., Ajmer, Rajasthan.

[28] Yadav, L. (2010). In vivo and in vitro phytochemical studies of two medicinally important plants belonging to family Menispermaceae. Ph.D. Thesis, M.G.S Univ. Bikaner, Rajasthan .

Table 1.1: Effect of Growth Hormones on Ascorbic Acid Content (mg/100 g.d.w.) IN A. marmelos and M. oleifera In Vitro (At Maximum GI)

\begin{tabular}{|c|c|c|c|c|c|c|c|}
\hline \multirow{3}{*}{ Name of Plant } & \multirow{3}{*}{ Sd MS Medium } & \multicolumn{6}{|c|}{ Growth Hormones } \\
\hline & & \multicolumn{3}{|c|}{$I A A / L$} & \multicolumn{3}{|c|}{$N A A / L$} \\
\hline & & $1 m g$ & $2 m g$ & $3 m g$ & $1 m g$ & $2 m g$ & $3 m g$ \\
\hline A.marmelos & $0.68 \pm 0.04$ & $0.71 \pm 0.03$ & $0.74 \pm 0.05$ & $0.65 \pm 0.04$ & $0.71 \pm 0.03$ & $0.73 \pm 0.04$ & $0.63 \pm 0.05$ \\
\hline M. oleifera & $0.84 \pm 0.05$ & $0.87 \pm 0.04$ & $0.90 \pm 0.06$ & $0.81 \pm 0.05$ & $0.86 \pm 0.04$ & $0.89 \pm 0.05$ & $0.80 \pm 0.04$ \\
\hline
\end{tabular}

Values are mean of five replicates $\pm \mathrm{SD}$

Table 1.2: Effect of Salts on Ascorbic Acid Content (mg/100 g.d.w.) IN A. marmelos and M. oleifera In Vitro (At Maximum GI)

\begin{tabular}{|c|c|c|c|c|c|c|c|}
\hline \multirow{3}{*}{ Name of Plant } & \multirow{3}{*}{ Sd MS Medium } & \multicolumn{6}{|c|}{ Salts } \\
\hline & & \multicolumn{3}{|c|}{$\mathrm{NaCl} / \mathrm{L}$} & \multicolumn{3}{|l|}{$\mathrm{KCl} / \mathrm{L}$} \\
\hline & & $10 m g$ & $20 m g$ & $30 m g$ & $10 \mathrm{mg}$ & $20 m g$ & $30 m g$ \\
\hline A.marmelos & $0.68 \pm 0.04$ & $0.71 \pm 0.05$ & $0.67 \pm 0.06$ & $0.64 \pm 0.05$ & $0.70 \pm 0.05$ & $0.66 \pm 0.04$ & $0.62 \pm 0.03$ \\
\hline M. oleifera & $0.84 \pm 0.05$ & $0.87 \pm 0.06$ & $0.82 \pm 0.06$ & $0.80 \pm 0.05$ & $0.85 \pm 0.05$ & $0.82 \pm 0.04$ & $0.80 \pm 0.04$ \\
\hline
\end{tabular}

Values are mean of five replicates \pm SD 